\title{
Giant Fibrous Epulis: A Case Report of a Benign Mass of the Oral Cavity
}

\author{
Melissa Laus $^{1 *}$, Manuel Antonio Conti ${ }^{2}$, Adelchi Croce ${ }^{1}$ \\ ${ }^{1}$ ENT Department, University “G D’Annunzio” of Chieti-Pescara, Hospital “SS Annunziata”, Via dei Vestini, Italy \\ ${ }^{2}$ University “G D’Annunzio” of Chieti-Pescara, Hospital “SS Annunziata”, Via dei Vestini, Italy \\ Email: ${ }^{*}$ Melissa.laus@hotmail.it
}

How to cite this paper: Laus, M., Conti, M.A. and Croce, A. (2016) Giant Fibrous Epulis: A Case Report of a Benign Mass of the Oral Cavity. International Journal of Otolaryngology and Head \& Neck Surgery, 5, 228-232.

http://dx.doi.org/10.4236/ijohns.2016.56035

Received: October 14, 2016

Accepted: November 20, 2016

Published: November 23, 2016

Copyright $\odot 2016$ by authors and Scientific Research Publishing Inc. This work is licensed under the Creative Commons Attribution International License (CC BY 4.0).

http://creativecommons.org/licenses/by/4.0/

\begin{abstract}
The epulis is a relatively frequent benign oral lesion that originates from the gingival and which has no degenerative potential. A 73-year-old-woman came to our attention for a mass, located in the oral cavity and more precisely in the right inferior maxillary alveolar ridge, that the patient firstly noticed 2 years earlier. Its dimensions increased over time and now were relevant. The mass was mobile, and non-ulcerated e did not evoke pain when palpated. It was characterized by a thin pedicle and its resection, under local anesthesia, allowed a complete removal of the mass itself. The histological examination showed a fibrous and plasmacellular epulis with calcific spots and mixoid aspects. We here report this case for the unique dimensions of this epulis and in order to give a useful example that could help in the differential diagnosis of the lesions located in the oral cavity.
\end{abstract}

\section{Keywords}

Epulis, Pedunculated Mass, Gingival Disease, Oral Pathology, Diagnosis

\section{Introduction}

The epulis is a relatively frequent benign lesion of the oral cavity [1]. The name derives from the ancient Greek and is an aspecific clinical term that bares a topographic meaning, indicating a lesion located over the gengiva [2] [3]. It is twice more common in females and the reasons for this remain unclear [4]. There are four types of epulides, depending on the prevalent histological component: fibrous, granulomatous (pyogenic granuloma), angiomatous and giant cells epulis. According to some authors, they correspond to different developing stages of a single pathological entity that, at the initial stages, would be rich with vascular and cellular components while the fibrous constituent progressively increases over time. It usually appears as a single pedunculated le- 
sion rising from the maxillary alveolar ridge. It is indolent and the dimensions may considerably vary. Its consistency as well is variable and the color depends on the prevalent histologic component ranging from pink to dark red [5]. The etiopathogenesis is not completely clear but seems to be related to several factors in which a key role is played by the reactive inflammatory component that determines its action on cells within the parodontal ligament or the periostium. Poor oral hygiene seems to be a predisposing factor [6]. The fact that they are more common in some conditions characterized by hormonal disequilibrium, such as pregnancy, supports the hormonal hypothesis [7]. Likewise, a chronic and recurrent traumatism may induce an exuberant or excessive tissue response [1].

\section{Case Report}

A 73-year-old woman, affected by congenital hypothyroidism, arterial hypertension, type 2 diabetes mellitus, came to our attention for a mass, located in the oral cavity and more precisely in the right inferior maxillary alveolar ridge (Figure 1(A)), that she firstly noticed 2 years earlier. Its dimensions increased over time and now were relevant $(4.5 \times 3 \times 3.1 \mathrm{~cm})$ (Figure $1(B))$. The mass appeared nodular, non-ulcerated, pink and white and its consistency was tough. It was mobile, anchored to the gengiva via a thin pedicle and did not evoke pain when palpated. We firstly planned to perform a biopsy, but, despite its relevant dimensions, it resulted easily clivable in the reduced space of the oral cavity, therefore we decided to completely remove it by resection of its thin pedicle, under local anesthesia. We then applied some bioadsorbable sutures to stop the subsequent mild hemorrhage. The alveolar ridge where the pedicle was anchored was intact. Macroscopically, the lesion appeared homogeneous and, on cut surface, showed a white aspect with a fibrous consistence and calcific spots. At the microscopic examination, the lesion appeared densely fibrous with lots of plasmacellular infiltrates surrounding vascular structures (Figure $2(\mathrm{~A})$ ). At the immunoistochemistry study, the plasmacellules were CD138 positive (Figure 2(B)) and CD56 negative and Kappa (Figure 2(C)) and Lambda (Figure 2(D)) chains positive, features that ruled out markers of atypia and eventually led to the diagnosis of fibrous and plasmacellular epulis with calcific spots and mixoid aspects.

\section{Discussion}

The term epulis was firstly introduced by Virchoff in 1864 and, later, its histological variants have been described (fibrous, granulomatous, angiomatous and with giant cells).

Our case report concerns a fibrous epulis in an advanced stage of growth. Some authors believe that the various forms of epulides are distinct entities, while others think that they are evolutionary stages of the same initial lesion. We agree with the latter.

Usually, the dentists represent the professional figures to initially deal with this pathological entity. Instead, in our case, the patient was sent by the general practitioner.

Sometimes, inexpert doctors mistake large or recurrent epulides for malignant lesions, such as fibrosarcoma, Burkitt's lymphoma, or squamous cell carcinoma [5]. For 


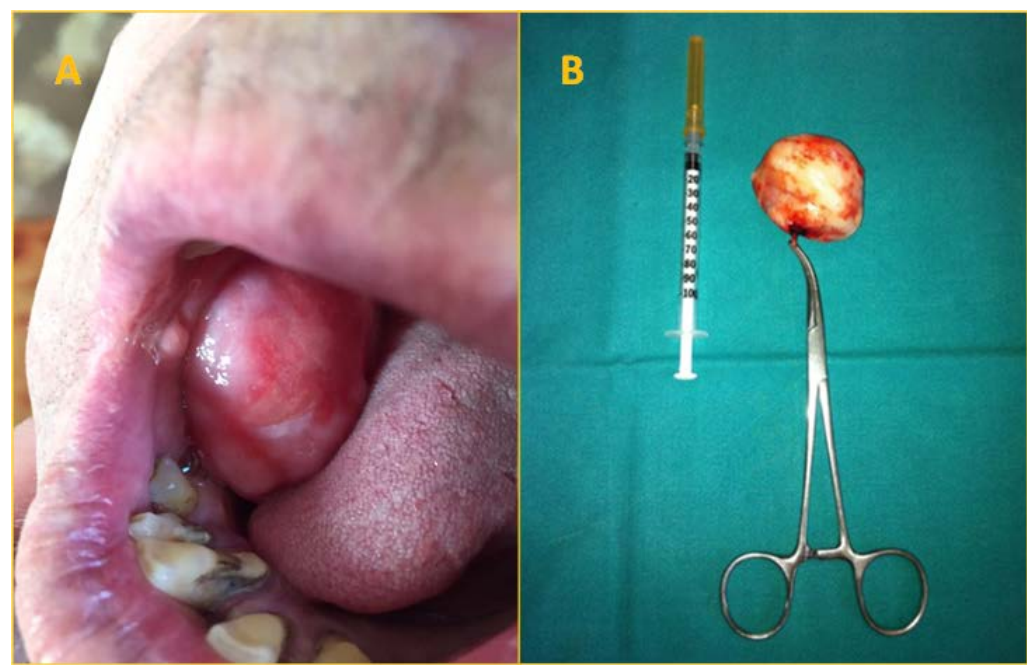

Figure 1. Clinical and macroscopic features: (A) the epulis in the right inferior maxillary alveolar ridge; (B) the epulis with the thin pedicle.

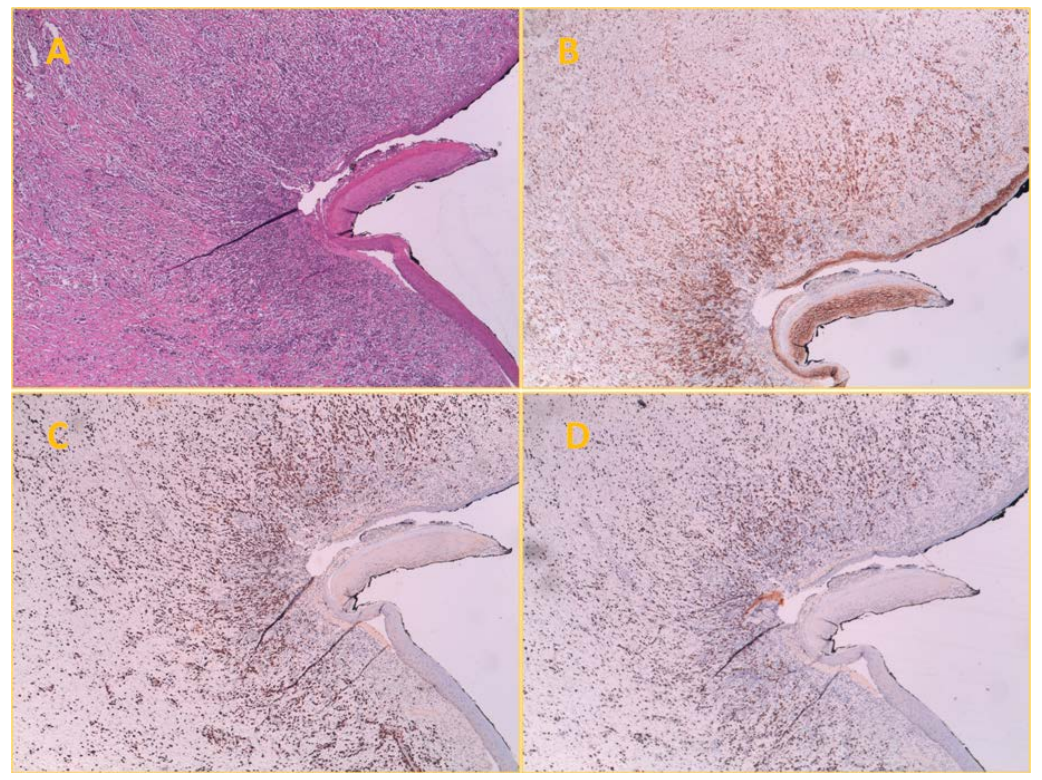

Figure 2. Histological and immunohistochemical sections: (A) hematoxylineosin staining, original magnification 4×; (B) plasmacellules CD138+; (C) plasmacellules Kappa+; (D) plasmacellules Lambda+.

the purpose of differential diagnosis, the histological examination is fundamental [8]. In our case report the easy removal of the mass allowed us to avoid to firstly perform a biopsy and therefore prolong the resolution of the clinical problem.

In literature there is agreement that the treatment of the epulides consists of the complete removal together with the underlying periostium associated with a thorough curettage of the bone and that the local irritative factors should also be removed [1]. When these lesions arise from the parodontal legament of a tooth, it should also be performed a radicolar levigature in order to remove the tissue which probably give ori- 
gin to them.

These lesions can recur, at a rate of about the $10 \%$ [1], and, in these cases, it might be necessary to remove the tooth associated with the lesions themselves.

In our case, given the presence of a very thin pedicle, we decided to remove the mass without touching the underlying bone of the alveolar ridge, and, after a follow up of about 6 months, the lesion has not recurred.

The way we decided to remove the lesion is, in our opinion, applicable whenever the lesion shows a very thin stalk and no gingival or bone alteration can be detected at the site of its implantation.

\section{Conclusions}

The diagnosis and treatment of fibrous epulis may sometimes be troublesome even for experienced clinicians, especially in areas such as ours (otolaryngologists) where there is usually a delay in presentation by the patients.

Adequate excision and histological examination of all tissues excised were found to be the best management procedure for fibrous epulides.

Multiple recurrences due to inadequate removal of the lesion may create doubts about its nature in the surgeon's mind or may worry the patient unnecessarily.

\section{Author's Contributions}

Melissa Laus concepted the study; Melissa Laus and Manuel Antonio Conti wrote the text; Adelchi Croce reviewed the paper and the English text.

\section{Conflict of Interests}

Melissa Laus, Manuel Antonio Conti and Adelchi Croce declare that they have no conflict of interests.

\section{Acknowledgements}

The authors would like to thank the patient for providing consent to use her photograph in this article.

\section{References}

[1] Fonseca, G.M., Fonseca, R.M. and Cantìn, M. (2014) Massive Fibrous Epulis: A Case Report of a 10-Year-Old Lesion. International Journal of Oral Science, 6, 182-184. https://doi.org/10.1038/ijos.2013.75

[2] Akazane, A. and Hassam, B. (2014) Images in Medicine. Epulis: à propos d'un cas. Pan African Medical Journal, 17, 19. https://doi.org/10.11604/pamj.2014.17.19.2997

[3] Rajanikanth, B.R., Srinivas, M., Suragimath, G., et al. (2012) Localized Gingival Enlargement: A Diagnostic Dilemma. Indian Journal of Dentistry, 3, 44-48. https://doi.org/10.1016/S0975-962X(12)60013-6

[4] Pour, M.A., Rad, M. and Mojtahedi, A. (2008) A Survey of Soft Tissue Tumor-Like Lesions of Oral Cavity: A Clinicopathological Study. Iranian Journal of Pathology, 3, 81-87. 
[5] Ajagbe, H.A. and Daramola, J.O. (1978) Fibrou Epulis: Experience in Clinical Presentation and Treatment of 39 Cases. Journal of the National Medical Association, 70, 317-319.

[6] Awange, D.O., Wakoli, K.A., Onyango, J.F., et al. (2009) Reactive Localized Inflammatory Hyperplastic of the Oral Mucosa. East African Medical Journal, 86, 79-82.

https://doi.org/10.4314/eamj.v86i2.46939

[7] Todero, M.A., Monaco, A., D’Amario, M., La Carbonara, M. and Capogreco, M. (2013) Peripheral Gigant Cell Granuloma (Giant Cell Epulis) Associated with Metabolic Diseases: Case Report and Literature Review. Annali di Stomatologia, 2, 1-48.

[8] Canadian Institute for Health Information (2012) International Statistical Classification of Diseases and Related Health Problems. Vol. 1, Tabular List, 10th Revision, Canadian Institute for Health Information, Ottawa, 420.

Submit or recommend next manuscript to SCIRP and we will provide best service for you:

Accepting pre-submission inquiries through Email, Facebook, LinkedIn, Twitter, etc. A wide selection of journals (inclusive of 9 subjects, more than 200 journals)

Providing 24-hour high-quality service

User-friendly online submission system

Fair and swift peer-review system

Efficient typesetting and proofreading procedure

Display of the result of downloads and visits, as well as the number of cited articles

Maximum dissemination of your research work

Submit your manuscript at: http://papersubmission.scirp.org/

Or contact ijohns@scirp.org 